\title{
TITANIUM METAL MATRIX COMPOSITES FOR AEROSPACE APPLICATIONS
}

\author{
S. A. Singerman* and J. J. Jackson** \\ *Pratt \& Whitney \\ West Palm Beach FL \\ **GE Aircraft Engines \\ Lynn MA
}

\section{Abstract}

Aerospace engine and airframe designers are constantly seeking lighter weight high strength materials to reduce weight and improve performance of powerplants and aircraft. Titanium metal matrix composites (Ti MMCs) have offered the promise of significant weight savings since their initial development in the early 1960 s, but until recently, their inadequate quality and reproducibility combined with high processing and materials costs have prevented their introduction into production applications. This paper describes the state-of-the-art for Ti MMC aerospace fabrications, their potential payoffs and the recent advances in processing which are now leading to high quality, affordable Ti MMC components.

\section{Introduction \& Historical Perspective}

Over the past 30 years, titanium metal matrix composites (Ti MMCs) have been under considerable development and evaluation for use in aircraft engine and airframe applications. For airframers, the high specific modulus of Ti MMCs has been the impetus, ${ }^{(1-3)}$ while engine makers have sought to take advantage of their high specific strength, especially for compressor rotor applications. (1) With the development of titanium aluminide matrix alloys ${ }^{(5,6)}$ which have temperature capabilities approaching $760^{\circ} \mathrm{C}\left(1400^{\circ} \mathrm{F}\right)$, Ti MMCs offer a potential $50 \%$ weight reduction in the hotter compressor sections now dominated by nickel based superalloys.

The introduction of Ti MMCs into high performance engine applications has been inhibited partly by the complexities of composite rotor fabrication. However, a more significant barrier is their high materials and implementation $\cos ^{(7)}$ which is mainly driven by low market volume. To overcome these barriers, Ti MMC components with higher volume applications are now being emphasized by Pratt \& Whitney (P\&W) and GE Aircraft Engines (GEAE) under the Advanced Research Projects Agency (ARPA)/Air Force sponsored Titanium Matrix Composite Turbine Engine Component Consortium (TMCTECC) Program. ${ }^{(8)}$ The high bypass commercial turbofan engines which will power long range aircraft into the next century can benefit greatly from the weight and operating cost reductions enabled by the selective use of Ti MMCs in their structures. These applications represent the size market needed to make Ti MMCs cost competitive (Ti MMCs at $\$ 1100$ per kilogram, $\$ 500$ per pound) for production introduction into engines or airframes. ${ }^{(8)}$ The following describes the status of Ti MMCs in terms of their demonstrated capabilities, potential payoffs and progress towards achieving affordable manufacture of components for aerospace applications.

\section{Processing \& Properties}

Ti MMCs which have demonstrated properties suitable for aerospace applications consist of conventional (Ti6Al4V, Ti6Al2Sn4Zr2Mo, etc.) and advanced ( $\mathrm{Ti}_{3} \mathrm{Al}$, TiAl, ctc.) titanium matrix alloys reinforecd with $30-40$ volume percent of continuous arrays of high strength ( $>3450 \mathrm{Mpa},>500 \mathrm{ksi}$ ), high modulus ( $380 \mathrm{Gpa}, 55 \mathrm{msi}$ ) SiC fibers. ${ }^{\S}$ These fibers are approximately $0.127 \mathrm{~mm}$ (5 mils) in dianeter and produced by chenical vapor deposition (CVD) with a $4 \mu \mathrm{m}(0.2 \mathrm{mil})$ carbon rich surface layer to enhance processability, fiber strength and achieve desired metal/fiber interface characleristics. ${ }^{(9,10)}$

\section{Processing}

For many years, Ti MMCs were primarily fabricated using foil/fabric

$\S$ SCS-6 SiC fiber made by Textron Specialty Materials, Lowell MA.

Trimarc1 SiC fiber made by AMERCOM, Inc., Chatsworth CA. processes consisting of alternating layers of woven fiber mats and $0.1-0.15 \mathrm{~mm}$ (4-5 mil) thick titanium alloy foils which were stacked up and vacuum hot press (VHP) or hot isostatic press (HIP) consolidated into multilayer composites. High foil costs associated with cross-roll processing of the preferred titanium alloys combined with high fiber costs and low volume demands caused Ti MMCs to only be considered for very high payoff applications. Additionally, a lack of reproducible quality for foil/fabric Ti MMC components precluded their introduction into any manrated aerospace applications. More recently, innovative processes including tape casting, $(11,12)$ induction plasma deposition (IPD), ${ }^{(13-15)}$ electron beam physical vapor deposition (EBPVD) fiber coating ${ }^{(16)}$ and fiber/wire cowinding ${ }^{(17)}$ have been developed in order to increase alloy flexibility and improve quality of Ti MMCs and at the same time reduce their fabrication costs.

The availability of this assortment of approaches now allows composite manufactures to select the method most suited for a particular component configuration. For example, airfoils, ducts and certain unidirectionally reinforced parts (actuators, exhaust link and struts) are most easily assembled using tape cast or IPD processed Ti MMC monotapes (a single Ti MMC ply). Cylindrical shapes requiring cross-ply layups which include shafts and ducts/cases can be more easily assembled with IPD processed monotapes which can be produced in wide sheets and maintain fiber position during asscmbly more cffectively than other methods. Rings for reinforcing rotor components can now be produced with tape cast strips, co-wound fiber/wire or coated fiber techniques more easily than with foil/fabric or IPD processes. Selectively reinforced structural applications are most cost effectively fabricated using coated fiber and pre-consolidated shapes made from tape cast or IPD monotapes. As a consequence of this increased flexibility for fahricating $\mathrm{Ti}$ MMC components, manufacturing costs are being dramatically reduced compared with previous foil/fabric components and quality significantly improved.

Having multiple fabrication options can aid the development of prototype components but it leads to a fractional market and resulting low volumes. One goal of the TMCTECC Program is to focus on a common material specification and mill product for fan applications in order to drive the cost of Ti MMCs to $\$ 1100$ per kilogram ( $\$ 500$ per pound).

\section{Propertics}

Some of the new processes cited above have now been developed to the point where a large enough materials property database exists to enable engine designers to make Ti MMCs serious candidates for weight reduction opportunities in advanced and growth versions of current engines. A comparison of properties for Ti MMCs and superalloys is shown in Table $\mathrm{I}$.

Table I Comparative Properties of Ti MMCs and Superalloys

\begin{tabular}{|l|c|c|c|}
\hline \multicolumn{1}{|c|}{ Property* } & $\begin{array}{c}\text { Conventional } \\
\text { Ti MMC }\end{array}$ & $\begin{array}{c}\text { Ti Aluminide } \\
\text { Ti MMC }\end{array}$ & Superalloys \\
\hline Density, $\mathrm{g} / \mathrm{cm}^{3}$ & 4.04 & 4.18 & 8.3 \\
\hline $0^{\circ}$ Stiffness, $\mathrm{GPa}$ & 200 & 242 & 207 \\
\hline $90^{\circ}$ Stiffuess, $\mathrm{GPa}$ & 145 & 200 & 207 \\
\hline Max Use Temp- ${ }^{\circ} \mathrm{C}$ & 538 & 760 & 1090 \\
\hline $0^{\circ} \mathrm{CTE},{ }^{\circ} \mathrm{C}^{-1} \times 10^{-6}$ & 7.20 & 7.92 & 13.0 \\
\hline $90^{\circ} \mathrm{CTE}^{\circ} \mathrm{C}^{-1} \times 10^{-6}$ & 8.91 & 9.18 & 13.0 \\
\hline
\end{tabular}

$* 0^{\circ}=$ Direction of Fiber, $90^{\circ}=$ Transverse to Direction of Fiber 
Achieving desired properties in Ti MMC structures is strongly dependent on preventing fiber damage or degradation during component fabrication while maintaining uniform fitber spacing illustrated in Figure I. When properly processied, conventional Ti MMCs can be reproducibly fabricated by tape casting or plasma deposition to achieve superalloy strengths up to $538^{\circ} \mathrm{C}$ $\left(1000^{\circ} \mathrm{F}\right)$ at half their density as shown in Figure 2. Advanoed titanium aluminide MMCs based on the $\mathrm{T}_{13} \mathrm{Al}$ intermetallic are being developed which may enable $\mathrm{T}_{1} \mathrm{MMC}$ use up to $760^{\circ} \mathrm{C}\left(1400^{\circ} \mathrm{F}\right)(5.6)$ The specifio modulus of Ti MMCs, which is especially important for structura applications, is also nearly double that of superalloys as shown in Figure 3 .

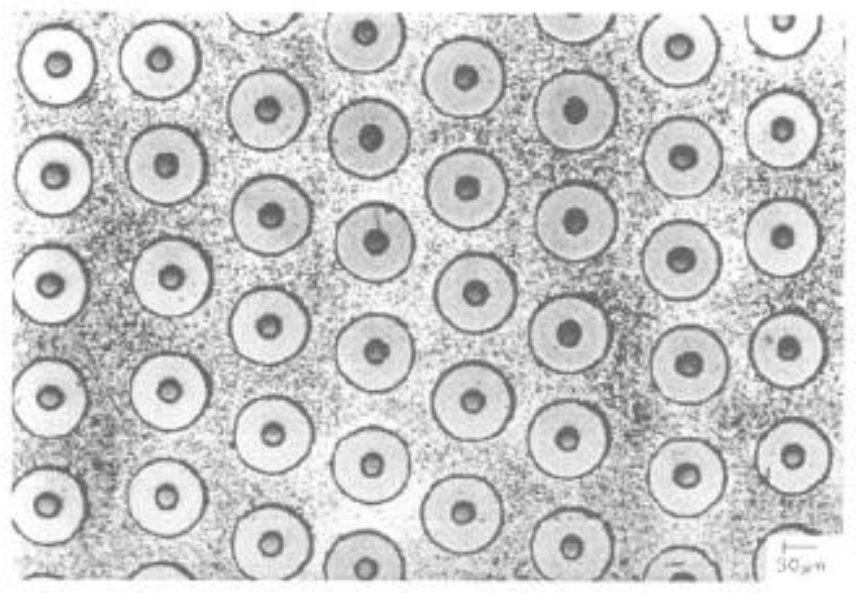

Figure 1: Typical microstructure of properly processed $\mathrm{Ti}_{1} \mathrm{MMC}$ (Ti6A12Sa4Zr2Mo/SCS-6) fabricared from plasma sprayed monotapes Note the unifarmly spaced, non-fouching fiber arriy which is critical to achicving predicted properties

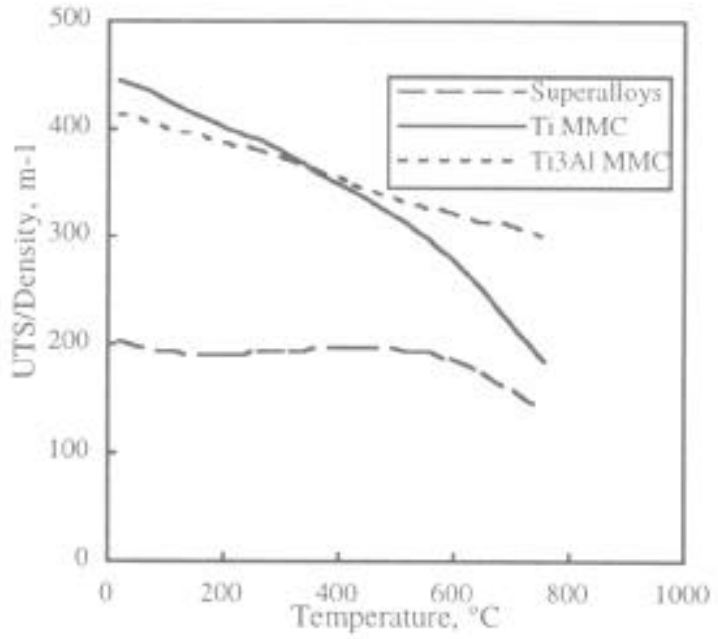

Figure 2: Comparison of specific strength of $\mathrm{Ti}$ MMCs and typical superalloys.

Of course, these excellent properties in the direction of fiber orientation can only be raken advantage of if the lower transverse properties of T1 MMCs do not fall below design requirements. Many applications have been identified that can cope with this anisotropy of $\mathrm{Ti} M \mathrm{MM}$ s and in some instances take advaatage of it

Other mechanical properties critical to therospace applications include low cycle fatigue (LCF) and fatigue crack growth (FCG). As shown in Figures 4 and 5. Ti MMCs exhibit LCF and FCG properties superior to superalloys when loaded in the fiber direction, even before considering their density benefit. However, transverse LCF and FCG for Ti MMCs are significantly lower that superalloys and therefore their use is restricted to those rotor applications which introduce low transverse cyclic stresses, Many rotor applications which satisfy this criteria have been identified by designers of the advanced military engines being developed under the Integrated High Performance Turbine Engne Technology (HPTET) Program. This program seeks to double the specific thrust of military engines and must rely heavily on the weight reduction potential of Ti MMCs and other advanced materials 10 do 80.

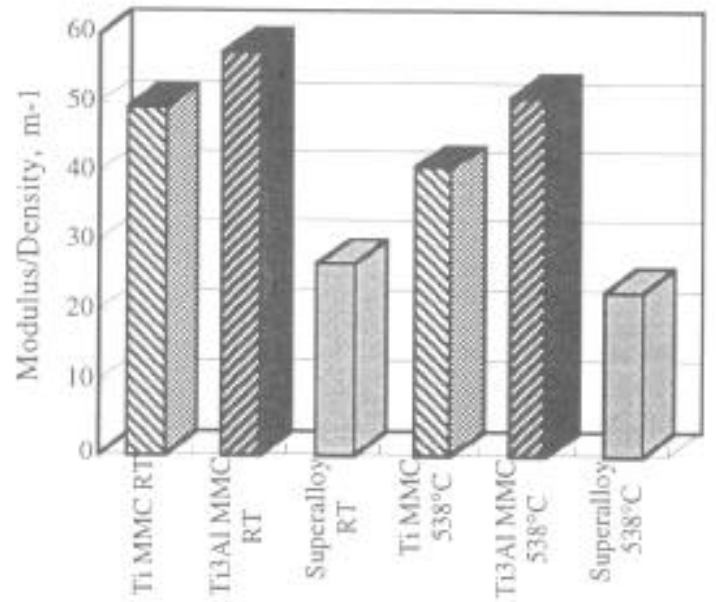

Figure 3: Comparison of specific modulus of $\mathrm{Ti} \mathrm{MMCs}$ and typical superalloys

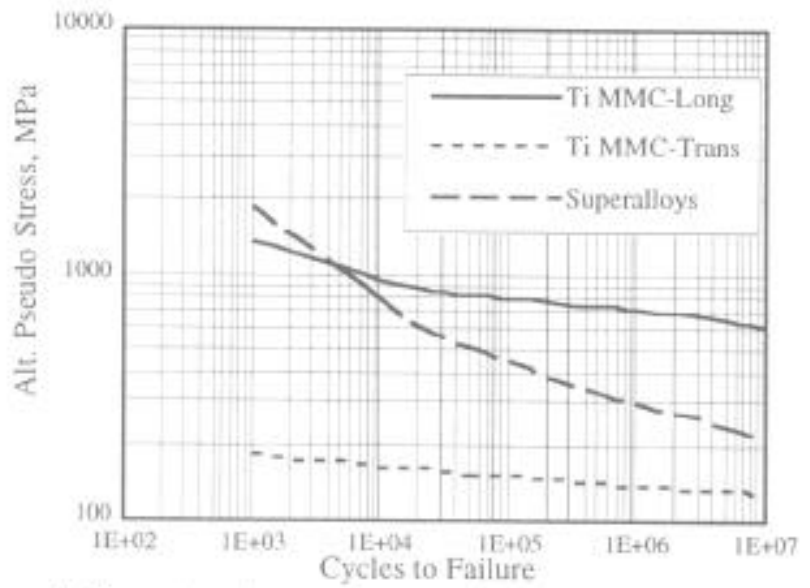

Figure 4: Comparison of room temperature low cycle fatigue capability of Ti MMCs with wrought IN718, a typical disk superalloy

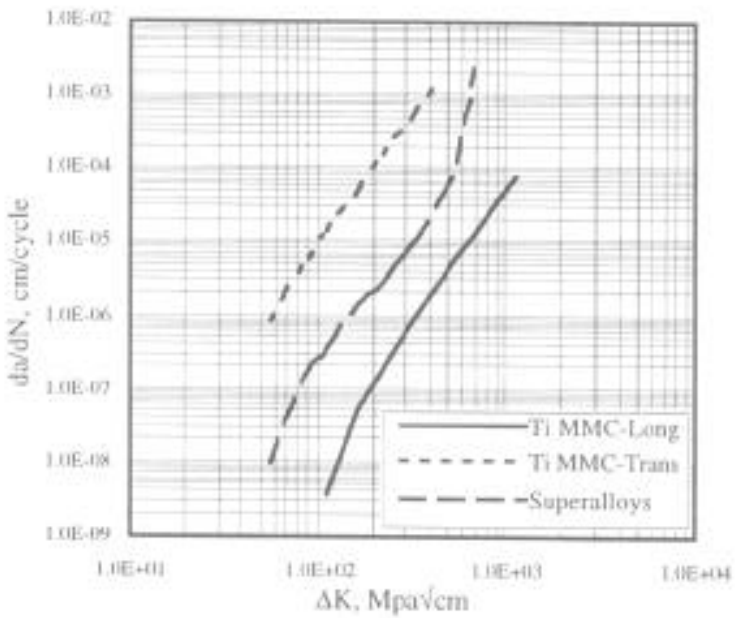

Figure 5: Comparison of roxm temperature fatigue crack growth hehavior of Ti MMCs with PM Rene 88DT, a typical disk superalloy especially designed for improved crack growth resistance 


\section{Potential Engine Applications \& Payoffs vs Risks}

Potential aerospace applications for Ti MMCs fall into several categories of payoff and risk. Figure 6 illustrates Ti MMC component opportunities and Table II lists the estimated payoffs, risks and relative costs associated with each. The applications are divided into categories of rotating and nonrotating parts which fall into various risk classifications. These risk classifications for Ti MMC components refer to the consequences of component failure or failure to perform per design intent. Weight savings are based on a comparison with the current part which may be titanium, nickel or steel alloys.

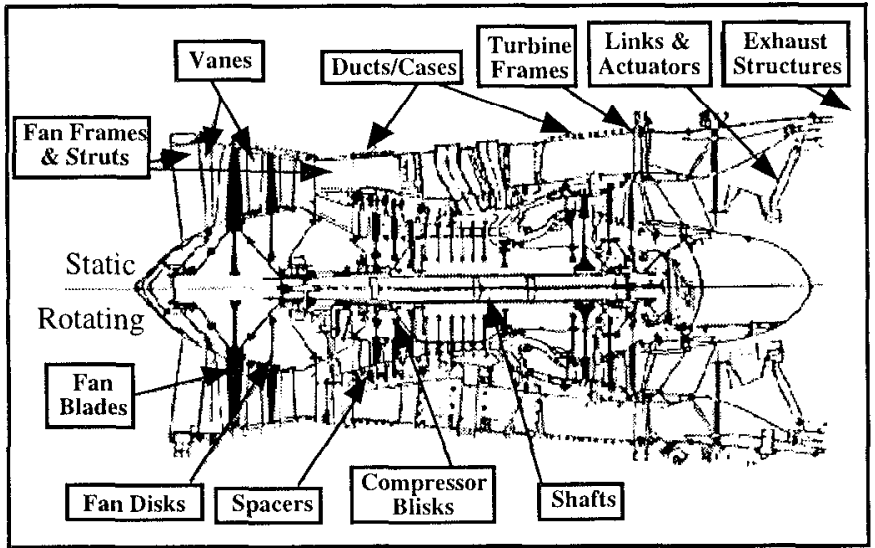

Figure 6: Potential engine applications for Ti MMCs.

\section{Rotating Components}

Rotating parts such as Ti MMC reinforced impellers, disks, integrally bladed rotors (1BRs) or blisks (bladed disks), blings (bladed rings) and blotors (bladed rotors) are high risk because they are inherently difficult to manufacture and their failures can destroy an engine. However, payoffs for Ti MMC rotors, in terms of engine performance and weight savings are the highest of any application. Rotor weight savings of from $30 \%$ to $>50 \%$ can be achieved with Ti MMCs with the added advantage of a larger free-hoop radius than either monolithic titanium or nickel disks. Ti MMC shafts represent a moderate to high risk application because, while they are more easily fabricated than disks, their failure in service could also be catastrophic. Payoffs for Ti MMC shafts are only moderate (up to about a
$30 \%$ weight savings) but they can lead to improved rotor dynamics. Nonload carrying spacers represent a low risk Ti MMC rotating application which may perform a critical engine function and thus justify their higher cost even though offering a small weight savings versus monolithic spacers.

Fan and compressor airfoils represent low to moderate risk rotating components since cngines arc designed to contain or otherwise cope with their failure and prevent engine destruction. Fabrication of Ti MMC containing airfoils is the least difficult of all rotating parts since their structures are usually two-dimensional layups with moderate curvature. In most cases, the payoff for Ti MMC airfoils on a direct substitution basis is relatively low (15-20\% weight savings) since they would replace titanium blades and thus have difficulty justifying their higher cost. However, in advanced high bypass engine applications like the PW4084, the specific stiffness of Ti MMC reinforced hollow fan blades (RHFBs) combined with a weight savings make them attractive enough to pursue. ${ }^{(8)}$ The payoff for Ti MMC airfoils in future "rubber engine" designs can be even more significant if the airfoil weight savings allows further reductions in disk and support structure weights.

\section{Non-Rotating Components}

Most non-rotating Ti MMC engine applications are of moderate to low risk. Pressure vessel and containment applications including ducts/cases represent typical examples of moderate risk parts. The modest payoff of $15-25 \%$ potential weight savings for these parts can be very significant due to the large size of these components. However, these weight savings must be traded off against the complexity and cost of their fabrication, which can be difficult due to the multitude of ports, attachments and other features prevalent. Stator vanes containing Ti MMC can not compete with current materials until titanium alloys for use above $760^{\circ} \mathrm{C}\left(1400^{\circ} \mathrm{F}\right)$ are fully developed and can be made into composites. To date, Ti MMCs based on the high temperature $\left(>815^{\circ} \mathrm{C},>1500^{\circ} \mathrm{F}\right)$ gamma TiAl intermetallic have not been successful due to the low ductility of these alloys combined with the significant SiC/TiAl coefficient of thermal expansion (CTE) mismatch. $(18,19)$

Structural components like struts and fan or turbine frames, whose primary function is to maintain engine shape and clearances under the wide range of mission loadings, are of moderate to low risk and rely heavily on material stiffness. Both weight savings and performance gains through reduced specific fuel consumption (SFC) can result from using Ti MMCs in these structures. On large bypass engines such as the GE90, fan frame weight savings of 10 to $15 \%$ are possible along with net cost savings of up to $35 \%$. These cost savings result from the use of lower cost aluminum or polymeric vanes which can be substituted for complex fabricated monolithic parts as a consequence of the selected application of $\mathrm{Ti} \mathrm{MMC}$ reinforced components. ${ }^{(20)}$

Table Il Potential Engine Applications and Payoffs for Ti MMCs.

\begin{tabular}{|c|c|c|c|c|c|}
\hline Category & Components & Engine Risk & Potential Payoff & $\begin{array}{c}\text { Relative* } \\
\text { Manufacturing } \\
\text { Difficulty }\end{array}$ & $\begin{array}{c}\text { Relative* }^{*} \\
\text { Manufacturing } \\
\text { Cost }\end{array}$ \\
\hline \multirow{4}{*}{$\begin{array}{l}\text { Rotating } \\
\text { Parts }\end{array}$} & $\begin{array}{l}\text { Disks, IBRs (Blisks), } \\
\text { Blings, Blotors, } \\
\text { Impellers, etc. }\end{array}$ & High & $\begin{array}{l}\text { - } 30 \% \text { to }>50 \% \text { Weight } \\
\text { - Larger Free-Hoop Radius } \\
\text { - Strength }\end{array}$ & 5 & 5 \\
\hline & Shafts & $\begin{array}{c}\text { Moderate } \\
\text { to } \\
\text { High } \\
\end{array}$ & $\begin{array}{l}\text { - } 15 \% \text { to } 30 \% \text { Weight } \\
\text { - Enhanced Stiffness } \\
\text { - Improved Rotor Dynamics } \\
\end{array}$ & 3 & 4 \\
\hline & $\begin{array}{l}\text { Fan \& } \\
\text { Compressor } \\
\text { Blades } \\
\end{array}$ & $\begin{array}{l}\text { Moderate } \\
\text { to } \\
\text { Low }\end{array}$ & $\begin{array}{l}\text { - } 15 \% \text { to } 20 \% \text { Weight (substitution) } \\
->30 \% \text { Weight (new designs) } \\
\text { - Improved Dynamics }\end{array}$ & 2. & 3 \\
\hline & Spacers & Low & $\begin{array}{l}\text { - } 10 \% \text { to } 15 \% \text { Weight } \\
\text { - Dimensional Stability }\end{array}$ & 4 & 4 \\
\hline \multirow{5}{*}{$\begin{array}{l}\text { Non-Rotating } \\
\text { Parts }\end{array}$} & Ducts/Cases & Moderate & $\begin{array}{l}\text { - } 15 \% \text { to } 25 \% \text { Weight } \\
\text { - Stiffness } \\
\end{array}$ & 3 & 3 \\
\hline & Stator Vanes & Moderate & $\begin{array}{l}\text { - } 5 \% \text { to } 15 \% \text { Weight } \\
\text { - Stiffness }\end{array}$ & 2 & 1 \\
\hline & $\begin{array}{l}\text { Struts, } \\
\text { Fan \& Turbine } \\
\text { Frames }\end{array}$ & Moderate & \begin{tabular}{|l} 
- $25 \%$ to $35 \%$ Weight \\
- Stiffness \\
- Improved SFC \\
\end{tabular} & 2 & 1 \\
\hline & Links, Actuators & Low & $\begin{array}{l}\text { - } 15 \% \text { o } 45 \% \text { Weight } \\
\text { - Stiffness, Stability } \\
\end{array}$ & 2 & 2 \\
\hline & $\begin{array}{l}\text { Exhaust Sidewalls \& } \\
\text { Structures }\end{array}$ & Low & $\begin{array}{l}\text { - } 25 \% \text { to } 40 \% \text { Weight } \\
\text { - Stiffness }\end{array}$ & 1 & 2 \\
\hline
\end{tabular}

\footnotetext{
* Relative Scale: 1 to 5 = Increasing Cost or Difficulty
} 
Other non-rotating parts being considered for Ti MMCs are low risk exhaust components including links, actuators, sidewalls and structural members for advanced military and commercial applications like the High Speed Civil Transport (HSCT) engine. Ti MMC links and actuators offer only a small overall engine weight savings but sidewalls and structural components in exhausts can represent a major portion of engine weight. Studies at GE and P\&W have shown that Ti MMCs could offer $20-40 \%$ weight savings for F120 exhaust nozzle structures compared to nickel components.

\section{Fabrication Demonstrations}

In the early 1970 s, fabrication development of Ti MMCs for compressor fan blade applications was started (21) Since that time, aumerous Department of Defense (DOD) and engine company funded programs have been conducted to determine and demonstrate the feasibility of fabricating the wide array of Ti MMC components cited above. The following is a sampling of the results of those efforts

\section{Disks. Blisks, Impellers}

Ti MMC reinforced disks offer lower density components and an increased hoop radius which can result in up to $50 \%$ weight reductions in compressors This high payoff potential has resulted in many DOD sponsored programs aimed at demonstrating fabrication feasibility and performance capability, (4,21,22) Those programs relied primarily on foil/fubric approaches to produce Ti MMC rings and encountered significant manufacturing difficulties but were ultimately successful at producing riags which achieved predicted burst and other performance capabilities. (23)

The potentially lower cost and simpler 'Ti MMC ring making processes based on powder and fiberiwire co-winding have been successfully demonstrated by engine and composite makers. Using a powder process, P\&W fabricated the $40.6 \mathrm{~cm}\left(16^{\prime \prime}\right)$ diameter Ti MMC reinforced IBR shown in Figure?. This rotor was proof spin tested and then tested in P\&W's XTC-6.5 IHPTET demonstrator engine where it met all performance requirements. $\{24\}$
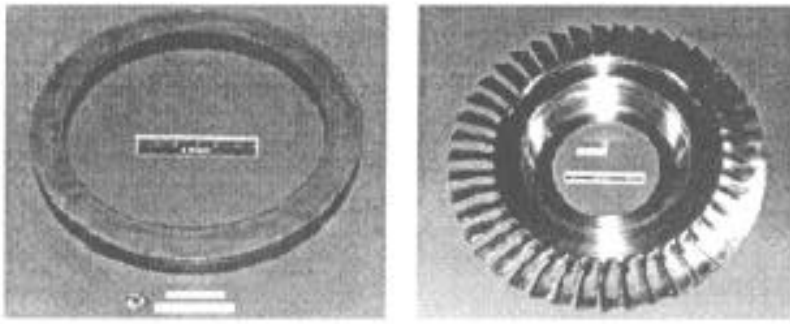

Figure 7: Ti MMC ring insert and corresponding integrally bladed rotor fabricated using powder process techniques and successfully tested in P\&W's XTC-65 IHPTET demonstrator engine

The simulated $17.8 \mathrm{~cm}\left(7^{\prime \prime}\right)$ diameter IBR shown in Figure 8 was fabricated by Atiantic Research Corporation (ARC). Wilmington MA, using their fiber/wire co-winding process, $(17)$ This component was subsequently spin tested to failure at $98 \%$ of its predicted hurst capability. A third acu approach to Ti MMC ring making has recently been demonstrated by $3 \mathrm{M}, \mathrm{St}$. Paul MN, which utilizes their EBPVD coated fiber technology, (16) Using Ti6Al4V coated SiC fiber consolidated into fully dense thin strips, a 16 ply, $10.2 \mathrm{~cm}\left(4^{\circ}\right)$ diameter Ti MMC ring was produced by $3 \mathrm{M}$ as shown in Figure 9 . Future rings of larger diameter will be made by this approach to determine its capabilities. The minimization of debulking requared for the $3 \mathrm{M}$ and $\mathrm{ARC}$ ring making approaches offers the distinct advantage of precise fiber location control, which can be critical to the effective use of Ti MMCs in rotors

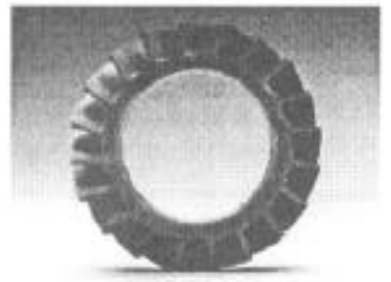

Figure 8: A simulated Ti MMC rotor fabricated by ARC using co-wound fiber/wire techniques and spin tested to failure at $98 \%$ of predicted capability

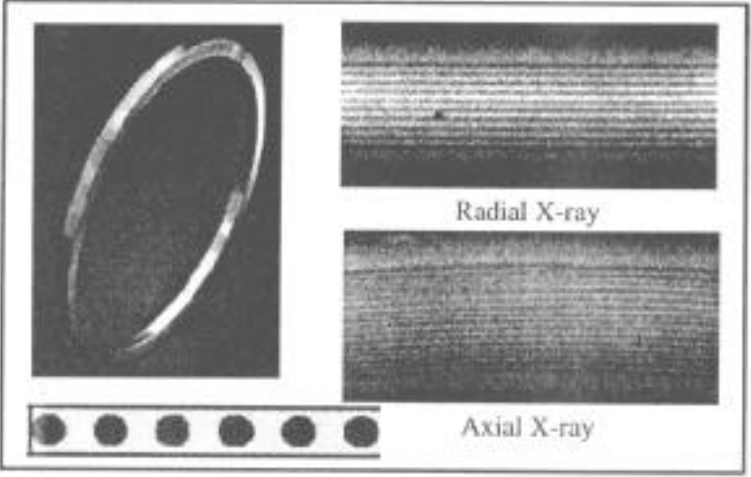

Figure 9: Demonstration Ti MMC ring fabricated by $3 \mathrm{M}$ using monotapes produced from coated SiC fibers. Note the precise positioning of fibers in both the radial and axial directions which is critical to design.

\section{Shants}

Development of titunium composite shafts started in the early 1980 s $|25-27\rangle$ and has progressed to the fabrication and testing of $\mathrm{Ti} \mathrm{MMC}$ power turbine shafts for small engines( 28$)$ and low pressure turbine (LPT) shafts for advanced IHPTET engines. (20) Figures 10 and 11 show a GE27 power turbine shaft and an XTE-45 LPT fan shaft, respectively, fabricated by Textron Specialty Materials. Lowell MA for GE Aircraft Engine. Ti MMC shafts of these types are typically fabricated with cross ply layups oriented frum $\pm 15^{\circ}$ to $\pm 45^{\circ}$ to the shaft axis. These layups enhance shaft stiffness and torque capability while reducing weight compared to nickel or steel shafts.

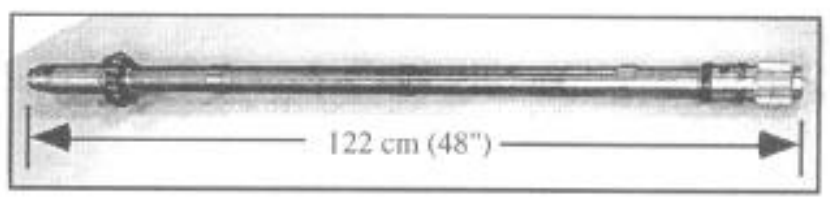

Figure 10. Early Ti MMC reinforced GE27 power turbine shaft fabricated by Textron using foil/fabric methods. This shaft was out of halance due to difficalty conwolling Ti MMC ply lecations and wall thicknesses.

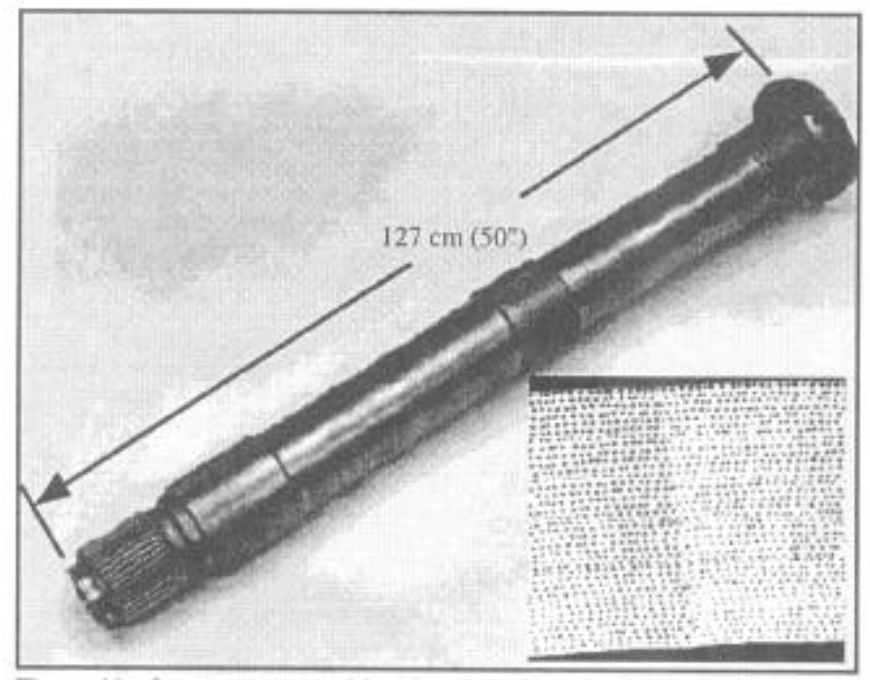

Figure 11: Low pressure turbine fan shaft for GE's XTE-45 demonstrator engine fabricated by Textron with IPD processed Ti MMC monotapes. This shafi exhibited no balance problems and exceeded all predicted strength and fatigue capabilities in component iests.

The $122 \mathrm{~cm}\left(48^{\prime \prime}\right)$ long, $5.07 \mathrm{~cm}\left(2^{\circ}\right)$ diameter power turbine shaft shown in Figure 10 was fabricated with 13 plies of $\pm 25^{\circ} \mathrm{Ti} \mathrm{MMC}$ using foil/fabric methods. This shaft exhibited predicted bending stiffness and natural frequencies but was out of balance due to wall thickness variations which resulted from ply wrapping difficulties. The $127 \mathrm{~cm}\left(50^{\circ}\right)$ long. $12.1 \mathrm{~cm}$ $\left(4.75^{\circ}\right)$ diameter LPT fan shaft shown in Figure II was fabricated more 
recently using 36 plies of $\pm 15^{\circ}$ oriented plasma sprayed Ti MMC monotapes This shaft was subsequently LCF tested to a nunout of 100,000 cyeles which exceeded predicted capability No significant balance problems were encountered with this shaft and natural frequencies were as predicted. A similar shaft is currently being fabricated for testing in the joint GE/Allison XTE-76 IHPTET demonstrator engine.

Blades

The ability to enhance airfoil stiffness and lower fan and compressor hlade weights by elimitiation of shrouds required for vibration mode control has made $\mathrm{Ti} M \mathrm{MMC}$ reinforcernent of these parts very attractive to engine designers. However, until recently, materials costs and fabricution issues (also cost drivers) have limited Ti MMC blade development. One program conducted by GE under Air Force sponsorship in the early $1980 \mathrm{~s}$ demonstrated that large Ti MMC reinforeed hollow fan blades like that shown in Figure 12 could be successfully fabricated using foil/fabric methods. ${ }^{331,31\}}$ These F110 configured blades had preconsolidated 18 ply unidirectional $\left(0^{\circ}\right)$ oriented Ti MMC reinforced skins on the concave and convex airfoil surfaces and when component tested, met or exceeded all predicted strength, stiffness, LCF and HCF capabilities.

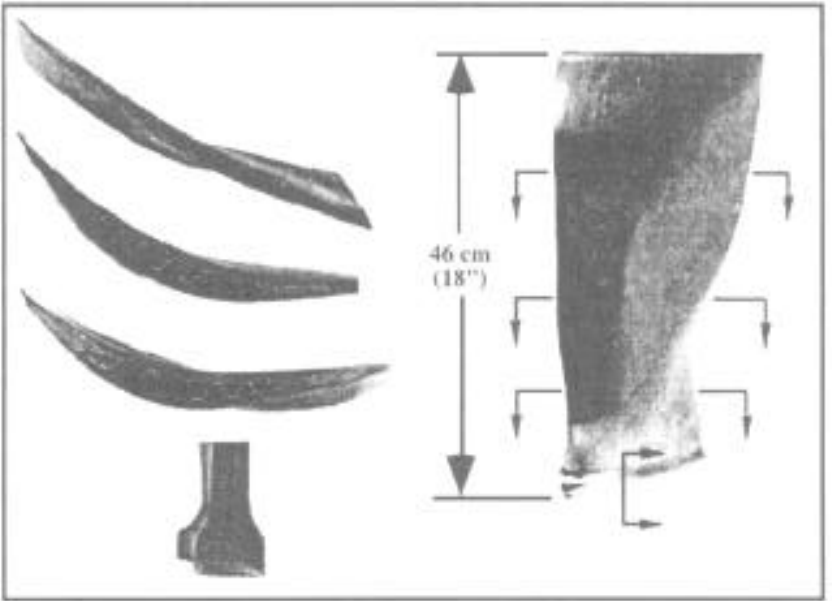

Figure 12: Hollow Ti MMC reinforced Fl10 fan blade fabricated by GE using preconsolidated foil/fabric skins produced by Textron. This blade demanstrated manufacturing fearibility and exhibited predicted performance benefits in component tests.

The encouraging results on the FI10 fan blade and the potential availability of lower cost Ti MMCs has led to further development of hotlow Ti MMC fan biades $(32,33)$ for P\&W military engines (similar in size to the GE blades) and for the high bypass PW4000 series commercial engine applications under the TMCTECC Program. ${ }^{(*)}$ The PW4000 fan blade application uses 8 pounds of unidirectional Ti MMC tape to stiffen the airfoil wall. Fous to eight plies of $50.8 \mathrm{~cm}$ by $101.6 \mathrm{~cm}\left(20^{\prime \prime}\right.$ by $\left.40^{\circ}\right) \mathrm{Ti}$ MMC tape are placed on either side of a hollow core region and subsequently HIP consnlidated Figure 13 shows a PW4084 fan blade fabricated on the TMCTECC Program

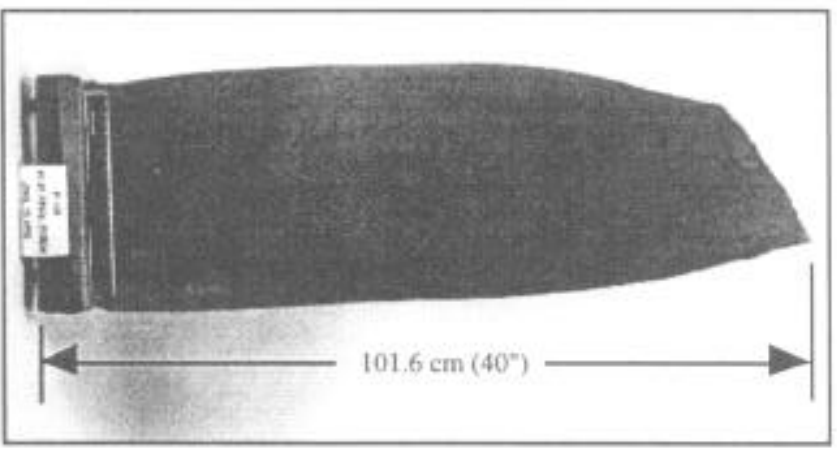

Figure 13: Hollow Ti MMC reinforced PW4084 fan blade fabricated on the TMCTECC Program.

\section{Ducts/Cases. Spacers}

Engune ducts or cases with Ti MMC reinforcements have been designed and fabricated by both GE and P\&W for their respective IPHTET engines. GE design studies have shown that weight savings from $20-30 \%$ can be achieved with Ti MMC ducts where ducted gas temperatures are in the $427.538^{\circ} \mathrm{C}$ $\left(800-1000^{\circ} \mathrm{F}\right)$ range and normally steel or nickel based ducts would be used. A prototype Ti MMC XTE-45 bypass duct which was fabricated for GE by Textron using IPD processed monotapes is shown in Figure 14. This duct utilized an 8 ply combination of unidirectional and cross-ply fiber layup to achieve design strength and stiffness requirements. A slightly different design case/duct which consisted of solid Ti MMC rods and struts was fabricated by Textron for P\&W using foil/fabric and wire winding methods This case was successfully proof tested at room temperature and exceeded all design predictions. In addition, a 16 ply conical shaped Ti MMC HPC spacer was fabricated by Textron. ${ }^{344}$ This thin shell ring consisted of $a \pm 15^{\circ}$ tape cast plies and was successfully spin tested by P\&W

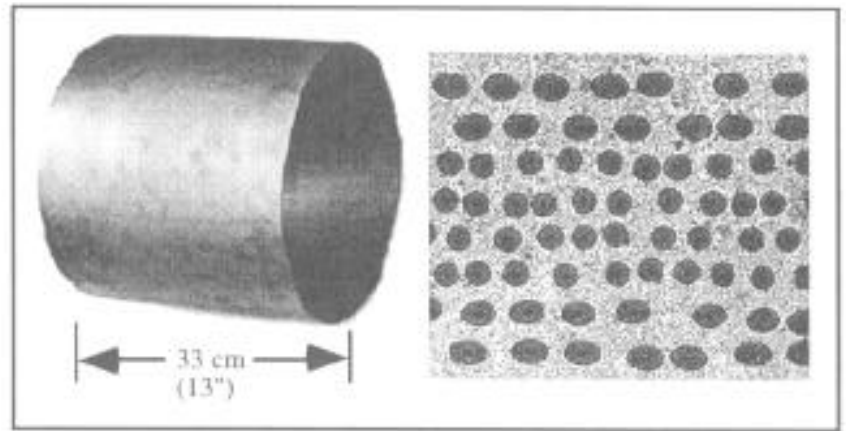

Figure 14: Prototype Ti MMC reinforced bypass duct fabricated for GE by Textron using plasma sprayed monotapes. Note the combined off-axis and unidirectional plies incorporated to meet design reyuirements

\section{Vanes. Frames. Struts}

Ti MMCs for non-load bearing vanes in engine structures offer little or ne payoff compared to monolithic or polymeric composite parts. However, where vanes help carry structural loads, the stiffness of Ti MMC can be of thenefit. This is particularly true where a combined vane/frame structure is used as in the GEY) engine. Under the GE portion to the TMCTECC Program several fan frame outlet guide vane (OGV) designs with Ti MMC reinforcements are being fabricated for component testing and to demonstrate manufacturing feasibility and costs. One OGV design of interest which consists of airfoil skins selectively reinforced with preconsolidated tape cast $0^{\circ}$ Ti MMC has been suecessfully fabricated as shown in Figure 15

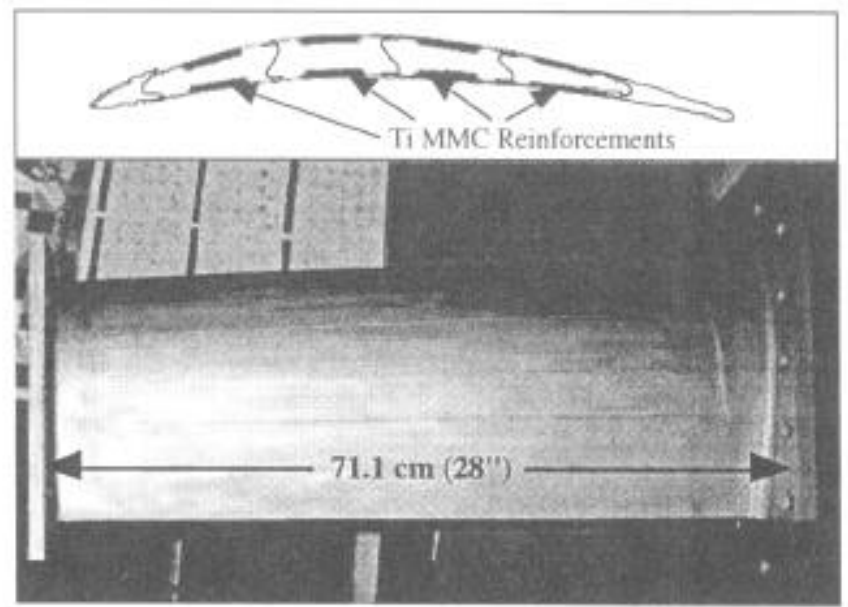

Figure 15: An outlet guide vane design for the GE90 fan frame fabricated on the TMCTECC program using preconsolidated tape cast Ti MMC inserts for the selectively reinforced airfoil skins. This is one of several cundidate designs being evaluated for potential weight and cost reductions.

Another OGV design being evaluated for the GE90 is a king strut which utilizes a bicasting approach developed by Howmet, Whitehall MI. This 
process was successfully demonstrated by Howmet in fabricating the Ti MMC reinforced prototype CF6 fan frame strut shown in Figure I6. A third OGV design being evaluated consists of highly reinforced leading and trailing edge Ti MMC elements which can be readily fabricated to near net shape with required bow and curvature using $3 \mathrm{M}$ s coated fibers. A $66 \mathrm{~cm}$ (26") long leading edge element fabricated by $3 \mathrm{M}$ on the TMCTECC Program is shown in Figure 17. These various OGV designs along with others are beingevaluated to identify the most cost effective and highest payoff design for potential production introduction into GE90 growth engine designs

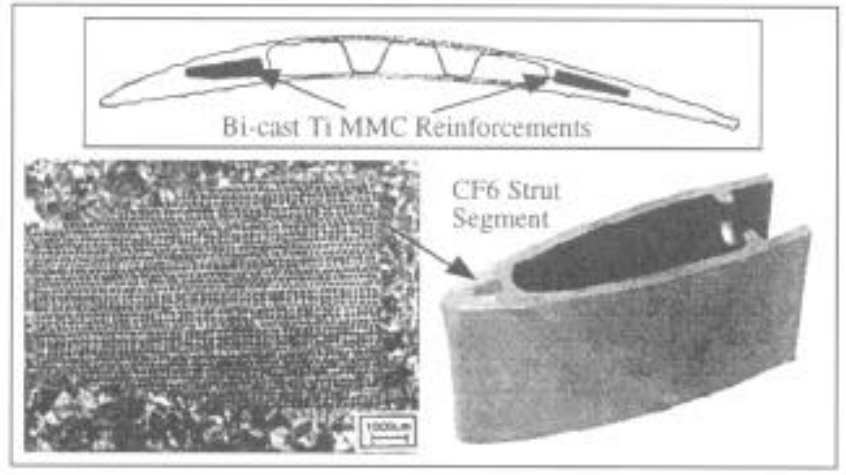

Figure 16: An outlet guide vane design for the GE90 fan frame fabricaled on the TMCTECC program using preconsolidated tape cast T1 MMC inserts in a king strut design based on Howmet's bicasting process previously demonstrated in GE's CF6 fan frame struts. This is one of several candidate designs being evaluated for potential weight and cost reductions.

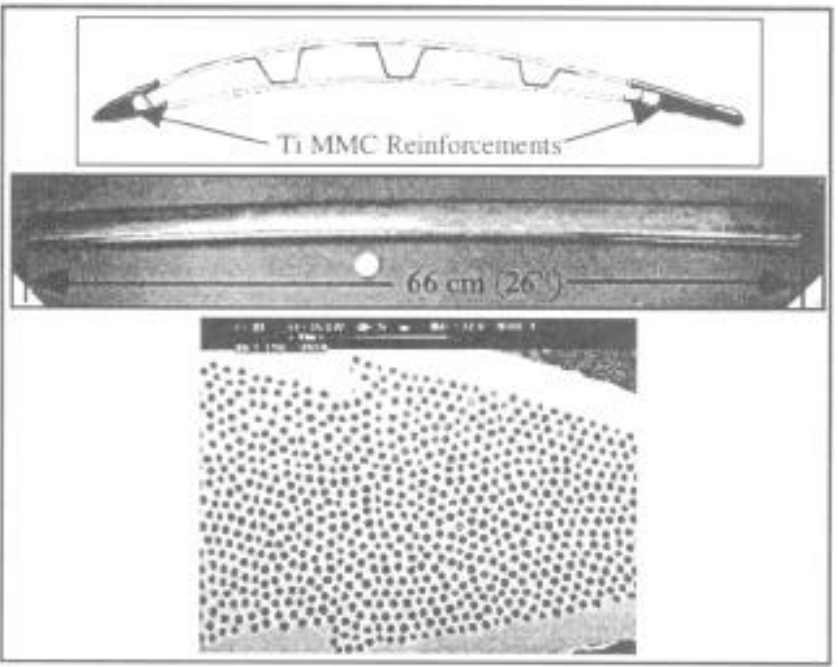

Figure 17: An cutlet guide vane for the GE90 fan frame fabricated on the TMCTECC program using the $3 \mathrm{M}$ coated fiber process to produce near net shape leading and trailing edge inserts. This is whe of several camdidate designts being evaluated for potential weight and cost reductions.

Solid high pressure compressor (HPC) blades with an 8 ply, $\pm 20^{\circ}$ Ti MMC reinforcemeat have recently been produced by P\&W using tape casting methods and successfully proof tested.

\section{Links, Actuators Nozzle Structures}

Relatively low risk parts such as links and actuators for moving exhaust flaps have been used as the first flight demonstration applications for Ti MMCs. In 1992, three Ti MMC compression links as shown in Figure 18 were installed in a GE F110-100 engine exhaust and flight tested for 31 hours in an Air Force F16 aurcraft with no visible distress. This flight testing was preceded by over 700 hours of factory engine tests which included over $37(x)$ after burner lights. These Ti MMC links were fabricated by Textron using IPD processed monotapes and replaced IN7 I links providing a $43 \%$ direct weight savings (35) However, the high Ti MMC eomponent cost prevented production implementation
Over the past two years, P\&W, ARC and Parker-Bertea have worked together to design and fabricate a $35.6 \mathrm{~cm}\left(14^{*}\right)$ long actuator piston rod for the F119 engine exhaust nozzle as shown in Figure 19,(36) Production quantities of $\mathrm{Ti}$ MMC reinforced piston cylinders with precisely located fibers were produced using ARC's fiber/wire co-winding process. These piston actuators, which offer a greater than $30 \%$ weight savings, exceeded all mechanical design requirements and have been qualified for use in production F119 engines. Ti MMC reinforced actuators are now also being considered for airframe applications.

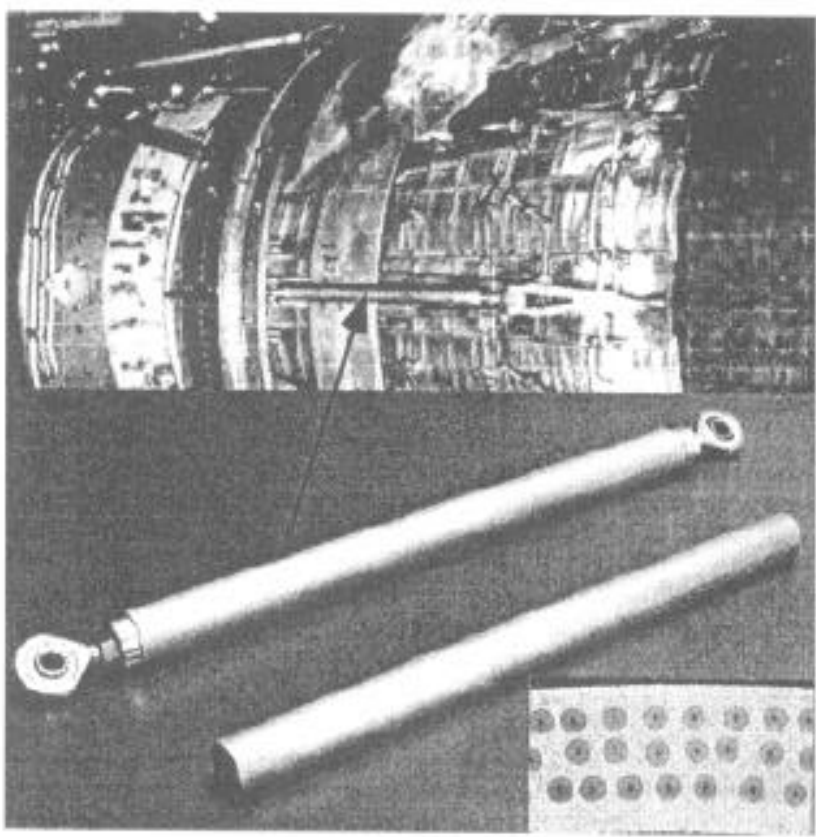

Figure 18: Ti MMC reinforced compression links for GE's F1 10-100 exhausi flaps fabricated by Textron using plasma sprayed monotapes. These links were saccessfully fight tested for puer 30 hours in an Air Force Fl6 with little evidence of distress.

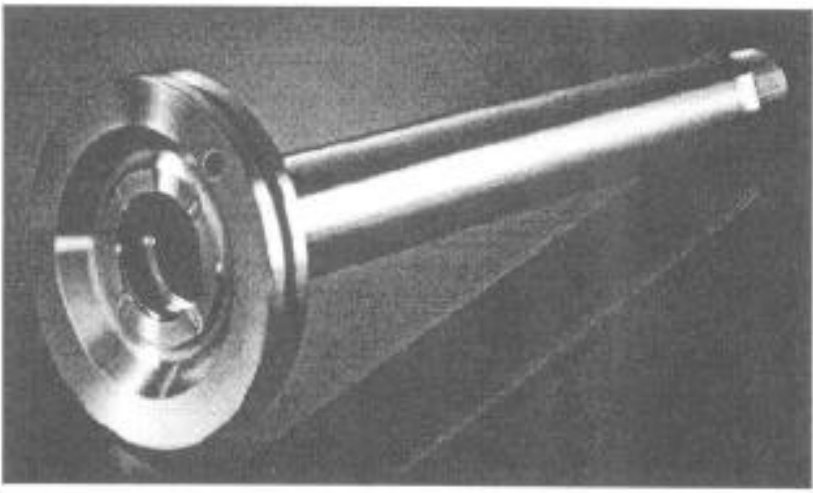

Figure 19: Ti MMC reinforced actuator piston rod fabricated by ARCIParkex-Bertea for P\&W's F1 19 engine for the F-22 fighter aircraft.

Fabrication approaches for large flat structures, 1-beam sections, box sections and other structural members reinforeed with Ti MMCs were extensively evaluated on an Air Force sponsored program by GE for potential F120 trggine exhaust structures, 37 ) While substantial potential weight savings were identufued, the high cost of Ti MMCs curtailed fabrication efforts and led to the TMCTECC initiative now in progress.

\section{Manufacturing Technology Staras}

Many fabrications processes exist that can meet the component fabrication needs for advanced aerospace applications. In order to focus the manufacturing infrastructure on a common approach for near term fan applications, the TMCTECC team has worked with the ARPA-sponsored High Performance Composites (HPC) Programi ${ }^{\text {34 }}$ ) to develop baseline specifications for SiCrTi6Al4V (TMC 2000 and 2001). These specifications 
are for green (unconsolidated) monotape and consolidated mill product. TMCTECC believes the key to establishing a high volume Ti MMC market is to agree to common material forms and common specifications.

During TMCTECC's Phase I activity, 3M, Textron, and ARC all produced material that met TMC 2000/2001 requirements. Textron and ARC are using a powder tape casting approach and $3 \mathrm{M}$ is EBPVD coating fibers. The current processes that produce the $\mathrm{SiC} / \mathrm{Ti} 6 \mathrm{Al} 4 \mathrm{~V}$ tape are generating very uniform microstructures and mechanical properties. In addition, the HPC Program is sponsoring the development and implementation of in-process monitoring sensors in the tape lines at ARC and Textron. Current capacity at the three suppliers totals more than 4535 kilograms $(10,000$ pounds) of tape per year. While the suppliers have not been able to achieve the TMCTECC Ti MMC material cost goal of less than $\$ 1100$ per kilogram ( $\$ 500$ per pound) at these volumes, they have validated their cost models to show that the goal can be achieved at production volumes greater than 6803 kilograms $(15,000$ pounds $)$ per year.

One way TMCTECC will be able to implement Ti MMC into its fan components is by using the strengths of the integrated product team philosophy. The designers, Ti MMC material suppliers, and component fabricators are working together to develop the optimum component based on performance, fabricability and cost. For GE and $\mathrm{P} \& \mathrm{~W}$ to replace the current bill of material $\mathrm{Ti}$ products, the cost of the Ti MMC containing component must be less than the production model. To achieve this while using $\$ 1100$ per kilogram ( $\$ 500$ per pound) Ti MMC material, the designer must understand how to maximize the composite benefits while minimizing its volume in the engine component. This leads the team to selecting simple shapes with little associated scrap during the fabrication process. With this approach, both the GE and P\&W TMCTECC applications are projecting a $30 \%$ cost savings compared with the components being replaced.

Unless a company identifies an enabling use for Ti MMCs, they must buy their way into a production application. The current Ti MMC material cost of greater than $\$ 11000$ per kilogram $(\$ 5,000$ per pound) is not competitive with any anticipated production opportunities. TMCTECC believes that achieving the cost goal of $\$ 1100$ per kilogram ( $\$ 500$ per pound) will lead to widespread Ti MMC use. The curve in rigure 20 shows the relationship between cost and volume projected by Ti MMC manufacturers. The projected DOD propulsion applications amount to less than 2268 kilograms $(5,000$ pounds $)$ per year, so additional commercial applications are needed to achieve the volume that will lead to supplier capitalization and the resulting economies of scale.

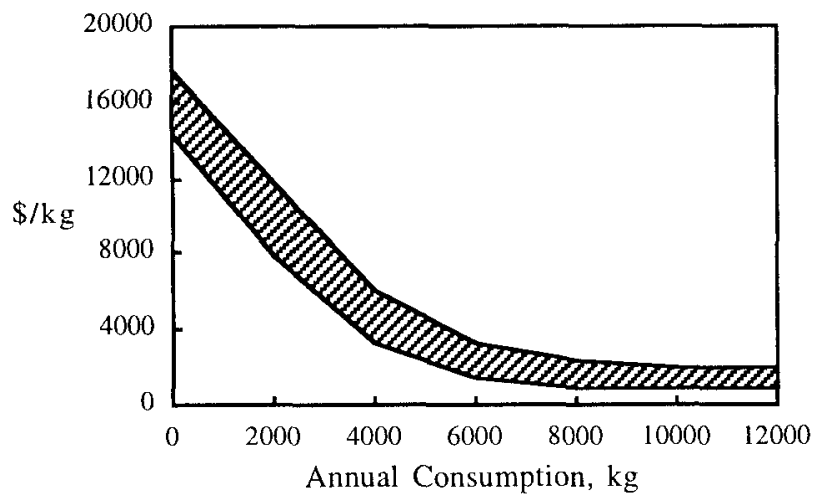

Figure 20: Projected cost of Ti MMCs as a function of market volume.

\section{Summary}

Over the past 20 years, the Ti MMC community has been able to demonstrate the benefits and fabrication feasibility of Ti MMC reinforced propulsion components. GE has gained flight experience with nozzle links and $\mathrm{P} \& \mathrm{~W}$ is inserting actuator piston rods in the F119 engine for the F-22 fighter aircraft. The material has been able to deliver the projected benefit in the applications that $\mathrm{GE}$ and $\mathrm{P} \& \mathrm{~W}$ have pursued. The current Ti MMC material fabrication processes are ready for production implementation and can routinely meet the TMC 2000/2001 specification requirements However, the suppliers and end users have been unable to generate sufficient demand to yield an affordable Ti MMC material. TMCTECC was formed to lake IHPTET developed Ti MMC material into production. The cost model and component demonstration articles are meeting the program milestones, but more work is required to achieve widespread implementation.

\section{References}

1. D.J. Dorr, "Two Sheet Available Fiber/Matrix Composite Design Development for Airframes," (Report AFWAL-TR-86-3065, WrightPatterson AFB OH, 1986).

2. M. Shea, "Low Life Cycle Cost Landing Gear," (Report WL-TR-913044, Wright-Patterson AFB OH, 1991).

3. J.T. Niemann, et al, "Titanium Matrix Composites, Volume IV Fabrication Development," (NASP Contractor Report 1145, NASP Materials and Structures Augmentation Program, NASP JPO, Wright-Patterson AFB $\mathrm{OH}, 1993$ )

4. R. Ravenhall, et al, "Composite Disk Validation Program," (Report WRDC-TR-90-2022, Wright-Patterson AFB OH, 1990).

5. T.E. O'Connell, "Production of Titanium Aluminide Products," (Report AFWAL-TR-83-4050, Wright-Patterson AFB OH, 1983).

6. J.J. Jackson, et al, "Titanium Aluminide Composites," (NASP Contractor Report 1112 , NASP JPO, Wright-Patterson AFB OH, 1991).

7. J.A. Graves, A.H. Muir, Jr. and C.G. Rhodes, "Manufacturing Science for Titanium Aluminide Composite Engine Structures," (Report WL-TR-924100, Wright-Patterson AFB OH, 1992).

8. R. Anderson, et al, "Titanium Matrix Composite Turbine Engine Component Consortium," (Quarterly Status Reports for Contract F33615-942-4439, WL/MTPM, Wright-Patterson AFB OH, November 1994 through April 1996).

9. A. Kumnick, et al, "Filament Modification to Provide High Temperature Consolidation and Fabrication Capability and to Explore Alternative Consolidation Techniques, "Final Report for Contract N0001982-C-0282, Naval Air Systems Command, Washington DC, 1983).

10. J.A. Cornie, R.J. Suplinskas and H. DeBolt, "Surface Enhancement of Silicon Carbide Filament for Metal Matrix Composites, " Summary Report for ONR Contract N00014-79-C-0691, Dept. of Navy, Arlington VA, 1981).

11. W.J. Grant and R. Lewis, "Continuous Powder/Fiber Tape Optimization Plan and Rationale for Powder/Fiber Tape Selection," (Report for Contract F33615-91-C-5728, Titanium Matrix Composite (TMC) Engine Conponents, Wright-Patterson AFB OH, 1993)

12. J.T. Niemann and J.F. Edd, "Fabrication of Titanium Aluminide Composites by Tape Casting," Titanium Aluminide Composites, P.R. Smith et al, eds., (Report WL-TR-91-4020, Wright-Patterson AFB OH, February 1991), 300 .

13. P.A. Siemers, J.J. Jackson, "Ti 3 Al/SCS-6 MMC Fabrication by Induction Plasma Deposition," Titanium Aluminide Composites, P.R. Smith et al, eds., (Report WL-TR-91-4020, Wright-Patterson AFB OH, February 1991), 233.

14. H. Gigerenzer, "Low Cost Metal Matrix Composites Preform Process," (Report WL-MT-63, Wright-Patterson AFB OH, 1992)

15. D.R. Pank and J.J. Jackson, "Metal Matrix Composite Processing Technologies for Aircraft Engine Applications", J. of Matls Engrg \& Perf., $2(3)(1993), 341$

16. J. Sorenson, et al, "Continuous Fiber Mctal Matrix Composites Model Factory," (Quarterly Status Report for ARPA Contract MDA972-90-C-0018, ARPA/CMO, Arlington VA, December 1995).

17. C.R. Rowe and S. Spear, private communications with authors, Atlantic Research Corporation, Wilmington MA, 9 March 1995.

18. G. DeBoer, et al, "Titanium Aluminide Composites," (Final Report for Contract F33657-86-C-2136, WL/POTO, Wright-Patterson AFB OH, 1993).

19. R. Holmes and D. Clemens, "High Temperature Metal Matrix Composite Compressor Rotor," (Final Report for Contract F33615-90-C2003, Wright-Patterson AFB OH, 1995).

20. J. Madge, "TMCTECC Phase I Reinforced Fan Frame Trade Studies," (Report for Contract F33615-94-2-4439, WL/MTPM, Wright-Patterson AFB $\mathrm{OH}, 31$ May 1995).

21. E.C. Stevens and D.K. Hanink, "Titanium Composite Fan Blades," (Report AFML-TR-70-180, Wright-Patterson AFB OH, 1970) 
22. G. Richardson, "Life Prediction of Composite Disks," (Report TR-922107, WL/POTC, Wright-Patterson AFB OH, 1992).

23. A.M. Zoss, et al, "Advanced Turbine Rotor Design," (Reports TR-862102 and TR-92-2020, WL/POTC, Wright-Patterson AFB OH, 1986, 1992).

24. W. Doehnert "Manufacturing Technology for TMC Ring Inserts," (Reports for Contract F33615-91-C-5723, Wright-Patterson AFB OH September 1991 to present).

25. S.R. Johnson and R. Ravenhall, "Metal Matrix Composite Shaft Research Program," (Report AFWAL-TR-87-2007, Wright-Patterson AFB $\mathrm{OH}, 1987$ )

26. D. Profant and G. Burt, "Manufacturing Methods for Metal Matrix Composite (MMC) Shafts," (Interim Reports for Contract F33615-80-C5176, Wright-Patterson AFB OH, 1981).

27. D. Gray, et al, "Titanium Metal Matrix Composite Shafts," (Report AFWAL-TR-84-4124, Wright-Patterson AFB OH, 1984).

28. E.M. Sterling and J.E. Bell, "Advanced High Stiffness Power Turbine Shaft," (Report USA AVSCOM TR 90-D-5, U.S. Army, AATD, Fort Eustis VA, 1990).

29. R. Barnes, et al, "Exoskeletal Structures Program," (Report WL-TR93-2034, Wright-Patterson AFB OH, 1993)

30. R. Ravenhall, "Advanced Reinforced Titanium Blade Development," (Report AFWAL-TR-82-4010, Phase I Final Report, Contract F33615-80-C3236, Wright-Patterson AFB OH, 1982).
31. R. Ravenhall, "Advanced Reinforced Titanium Blade Development," (GE Report TM89-357, Phase II and III Final Report, Contract F33615-803236, Wright-Patterson AFB OH, August 1989).

32. D. Kasperski "Reinforced Hollow Fan Blade (RHFB) PRDA II," (Reports for Contract F33615-90-C-2040, Wright-Patterson AFB OH, August 1990 to present).

33. D. Romlein, "XTC-65/3 ATEGG Core Fabrication and Test," (Reports for Contract F33657-86-C-2013, Wright-Patterson AFB OH, 1986 to 1993).

34. S. Skemp, "ATEGG MMC Rotor Spacers," (Reports for Contract F33657-90-C-2212, Wright-Patterson AFB OH, 1992).

35. J.J. Jackson, et al, "Titanium Matrix Composite Engine Components," (Reports for Contract F33615-91-C-5728, WL/MLLM, Wright-Patterson AFB OH, October 1991 to September 1993).

36. R.D. Tucker, "Lightweight Engine Structures and Drum Rotor," (Report WL-TR-95-2070, Wright-Patterson AFB OH, 1995)

37. R.R. Oliver, et al, "Manufacturing Technology for Metal Malrix Composite Exhaust Nozzle Components," (Final Report for Contract F33615-91-C-5730, WL/MTPM, Wright-Patterson AFB OH, 30 September 1994).

38. P. Parish, "High Performance Composites," (Reports for ARPA Contract MDA972-93-2-0008, ARPA/CMO, Arlington VA, May 1994 to present). 